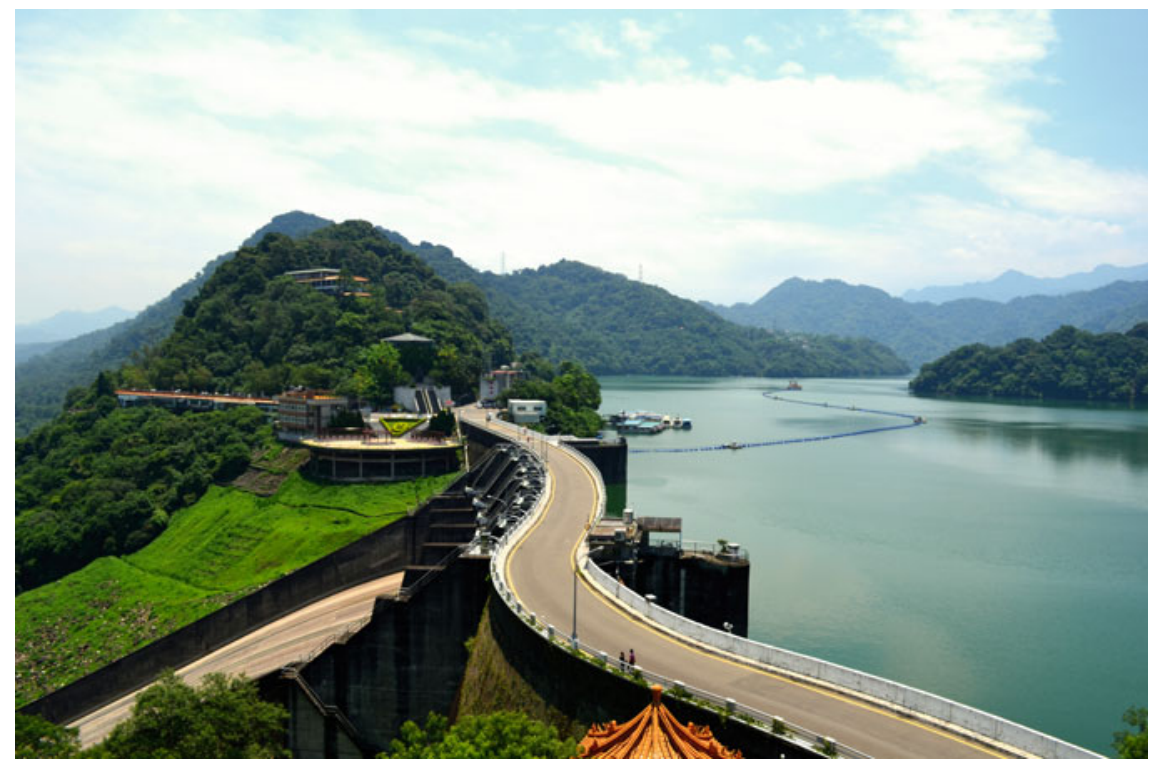

Shihmen Dam in Taoyuan County, Hua Lin, released under a Creative Commons AttributionNonCommercial-ShareAlike 2.0 Generic license 


\title{
Chapter 9 \\ How Citizens Reshaped a Plan \\ for an Aerotropolis and Preserved the Water Heritage System of the Taoyuan Tableland
}

\author{
Sinite Yu, Chung-Hsi Lin, Hsiaoen Wu, Wenyao Hsu and Yu-Chuan Chang
}

\begin{abstract}
Heritage preservation in Taiwan was for many years limited to a small group of art experts, who focused on masterpieces in museums or on magnificent architecture, disconnected from people's daily lives and current society. Others made efforts to enhance local cultures and encourage grassroot participation in heritage preservation, but, as heritage sites continued to be treated as single, unrelated objects, these efforts remained only loosely tied to local communities. A recent campaign for the preservation of the pond-canal system heritage in the Taoyuan tableland suggests a change of direction and indicates new opportunities for increased attention to and participation in heritage. In 2008, a plan for developing an airport-based metropolitan region, a so-called Aerotropolis, threatened the local water heritage infrastructure, including its distribution network and the local sustaining eco- and social systems. Opposition arose among a wide range of environmental and social groups, which weighed in on the importance of the water system. Together their stories wove a fine and unbreakable "web of narratives," which became a shield that successfully protected the water heritage. Water heritage, as a system of multiple sites that is by nature more relevant to people's daily lives, can benefit from such participatory preservation. Moreover, it is possible, too, that the conservation of heritage of all categories could find inspiration in this strategy.
\end{abstract}

Keywords Water heritage - Taoyuan tableland • Pond-canal system • Aerotropolis $\cdot$ Public participation

S. Yu ( $\varangle) \cdot \mathrm{H} . \mathrm{Wu} \cdot \mathrm{W}$. Hsu

Taiwan International Institute for Water Education, Taiwan, Republic of China

e-mail: dryu@ tiiwe.org.tw

C.-H. Lin

National Yunlin University of Science and Technology, Taiwan, Republic of China

Y.-C. Chang

HsingWu University, Taiwan, Republic of China

(C) The Author(s) 2020

C. Hein (ed.), Adaptive Strategies for Water Heritage,

https://doi.org/10.1007/978-3-030-00268-8_9 


\section{Introduction: Theoretical and Methodological Implications of Participatory Heritage Preservation}

The heritage debate of Taiwan has focused since the mid-twentieth century on constructing a narrative in line with the government's political objectives. After World War II, the Chinese nationalist government took Taiwan over from Japan and four years later retreated there from mainland China. With the hope of reconquering the mainland, the postwar government defined "cultural heritage" as the treasures brought from mainland China, including Chinese antiques and art masterpieces. This emphasis on the ties between culture and national identity was further enhanced when the Chinese Cultural Revolution began in 1966: the nationalists propagandized Taiwan as both the lighthouse of democracy and the guardian of Chinese culture. The most precious heritage, as taught in school, was the Chinese treasures in the Palace Museum in Taipei, a place designed in the style of a Chinese palace. Many famous buildings of this period, like the Grand Hotel, were built in similar style on the site of former Japanese temples, to proclaim the triumph of the Chinese over the Japanese in the war as well as the blooming of classic Chinese culture in Taiwan.

Ideas about cultural heritage in Taiwan were limited to single and mostly tangible objects for decades, quite disconnected from people's daily lives. Even after political ideologies became less important and influential in the 1980s, dominant approaches continued to view "cultural heritage" as individual buildings, constructions, and other objects that embody some important aspects of human civilization. They highlighted the splendor of single sites, but, when these places ceased to be active in their original roles, they became disconnected from the society they belong to and distant from people's lives or memories.

In recent years, more and more preservationists have adopted a new approach to enhance the value of cultural heritage: weaving a web of narratives that view multiple sites or items as a heritage network or system and inviting the people of the local community to participate in this narrative creation. This new method in many aspects echoes the concept of "cultural route" that emerged in the international community of heritage preservation in this century. But this chapter focuses on the distinctive Taiwanese context and gives credit to local devotees who, without being informed of the latest theories on cultural routes, developed something on their own. Their method has won some significant successes. This chapter discusses a recent campaign in Taiwan's Taoyuan tableland for protecting regional ponds and canals and suggests that participatory narrative weaving empowered that campaign. It further argues that this example shows how water infrastructure that is both parts of a network and close to people can boost both new heritage appreciation and participatory preservation in modern society.

Heritage preservation focusing on individual objects or sites has its benefits and setbacks. Most sites in this kind of preservation projects have some magnificence or beauty that can be easily discovered and demonstrated. Preservationists, researchers, and the government can thus invest their energy and resources on these single objects and make the most out of their investment. But this approach tends to handle heritage 
sites as treasures displayed in the museum window, and, as a result, often disconnect them from the context in which they were created. They are dead relics of past splendors. This focus could have some further negative consequences. First, the less a heritage site is connected to the society to which it belongs, the less important it becomes. When society changes and the heritage site ceases to function, this disconnection worsens and makes the site no longer relevant to its community. Second, disconnecting an item from its context often makes it difficult for people to apprehend the value of the context itself and the role this item plays in relation to other things in the same context or network (See: Lin 2017).

This is the problem that many heritage sites in Taiwan face. Take one example: The Lin family's mansion in Wufeng, Taichung, form the largest pre-modern residence owned by a civilian; it was built and expanded many times during the nineteenth century. Its importance lies in its architectural beauty, the Lin family's legendary wealth, and some major historic events related to the family. Lin Xian-Tang, a clan chief, actively advocated democracy during Japanese colonialism and sponsored the island's literary and art societies - many writers and artists met at the Lin mansion and garden. Though the Lin family occupies quite a few pages in Taiwan's history textbooks, and though the cultural values of the site are widely recognized by art and architectural historians, local people in Taichung stopped finding this heritage relevant to their community after the Lins ceased to be active in politics (See: Liu 2003).

Narrative weaving takes a very different approach to heritage preservation from what is described above (See: Lin 2017). It views single treasures as essential components of a larger network or system incorporating tangible and intangible elements. This more holistic view takes into account the context that produced, nourished, benefitted from, or expressed itself with the treasures. As the scope of inquiry enlarges, it is possible to link the system of treasures to more aspects of human history and society and appeal to some universal values. In this way, the heritage network becomes relevant to the experiences or memory of more people, and more important to the local community also increased. In addition, narrative weaving is a participatory project that invites all people related to the heritage site or system, members of local communities in particular, to take part by contributing their stories and opinions as well as discovering new meanings of the heritage site in the modern world.

Participatory narrative weaving arouses communal awareness of this heritage and stimulates greater participation in the definition and preservation of the heritage. The more these stories are told, the more important the heritage becomes in the life, history, and memory of the local community. This creates an interwoven Web, enriching the heritage's relevance and binding it with people's daily life and shared memory, and makes the heritage an indispensable part of the community. The significance and influence of the heritage may hence expand beyond the very specific context in which it was born and embody more universal values. Moreover, unlike the heritage preservation which was studied, defined and decided by a small group of experts and government officials, participatory narrative weaving encourages the local community to be very active, and participants are able to create new meanings and functions for the heritage and prolong its significance in today' fast- 
changing society. Finally, although participatory narrative weaving appears to need more resources than traditional preservation, paying attention to multiple sites, and including more participants, it is a more efficient use of resources in the long run: committed community members take heritage protection as their interests or duties and willingly donate their time and efforts. Today, the efficiencies are even greater as people can use Internet and social media to spreads news and information more easily and to solicit wider support.

Water heritage, particularly sites and systems still in operation, benefits in particular from this approach. As water penetrates every part of human life and human society, it is all too easy for people to overlook its importance. At the same time, participatory narrative weaving invites people to look at the contributions of the infrastructures and institutions that manage water resources for them, by bringing together stories of local water's close ties to the community's existence, industry, culture, etc. (See: Yu 2015). Any new story about the site or system, or any new participant in the heritage conservation project, empowers a virtuous cycle for the heritage's prolonged well-being.

\section{Historical Ponds and the Taoyuan Main Canal System}

Historical records of irrigation systems for agriculture in Taiwan can be traced back to the seventeenth century. After it took over southern Taiwan in 1624, the Dutch East India Company (VOC) brought in Chinese farmers to grow tropical crops and sugarcane and installed wells and ponds (See: Chang 2016). The commonly used concept and technology of water-retaining works (see Fig. 1a) in Taiwan can be attributed to the presence of the Dutch VOC on the island, as many man-made ponds (or Bei) are called "ponds of the red-haired" in historical maps and oral traditions (See: Yu 2017). Taoyuan, which lies in north Taiwan and was not occupied by the VOC during the seventeenth century, saw its first man-made pond on record in 1741. Documentations of later pond construction abound as Chinese immigrants brought the privatization of land ownership and the use of written contracts with them (See: Chen 2003a). A land lease of 1843 (see Fig. 1b) shows how a community settled land and water rights involving ponds and canals. The "Maps of Taiwan Fortresses", a survey published by the Japanese colonial government in 1904, were the earliest topographic maps of Taiwan (See: Government of Taiwan 1996). The survey (with 1/20,000 scale) detailed more than ten thousand man-made ponds (see Fig. 2a), varied in size and location, dotting the $900 \mathrm{~km}^{2}$ Taoyuan tableland like a starry sky, all built before the twentieth century. Google Earth's 2016 updated version shows that many of the ponds are still in existence today (see Fig. 2b). The comparison between the topographic evidence explicitly indicates the existence of many ponds on Taoyuan tableland landscape over centuries (See: Yu 2017).

Before the twentieth century, farmers in Taoyuan would build ditches or culverts to transport water from ponds to individual farmlands (Chen 2003a). But these networks of water management remained dispersed and on a small scale. After the Qing Empire 


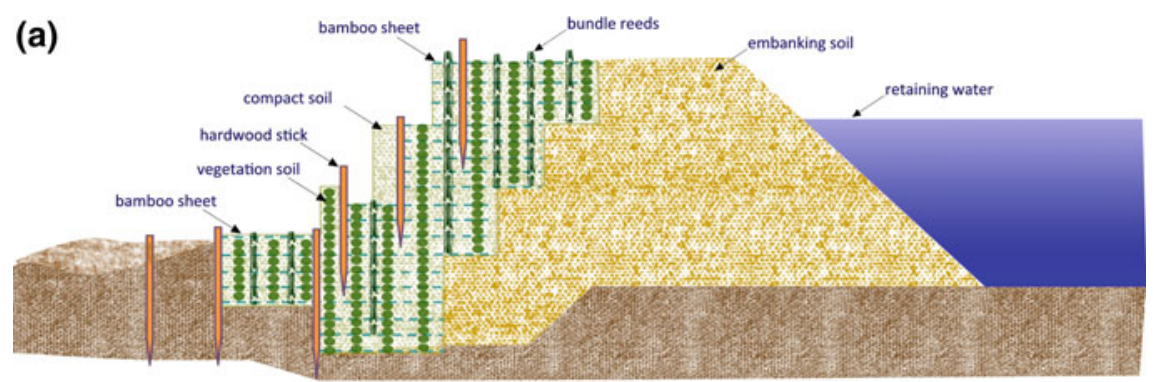

(b)

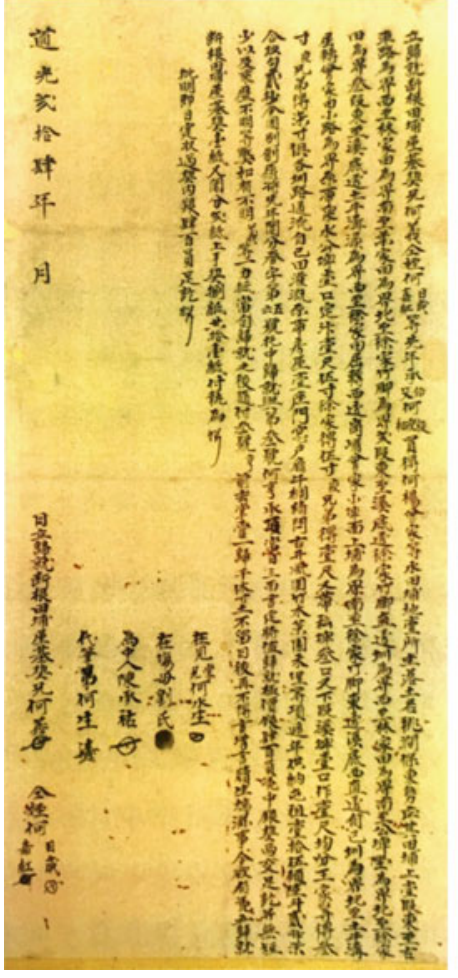

Fig. 1 Historic evidences of pond construction: a Schematic diagram of Dutch water retaining work in Taiwan (left), b Land lease copy in 1844 (right). Source https://blog.xuite.net; released under a Creative Commons Attribution-NonCommercial-NoDerivatives 4.0 International License 
(a)

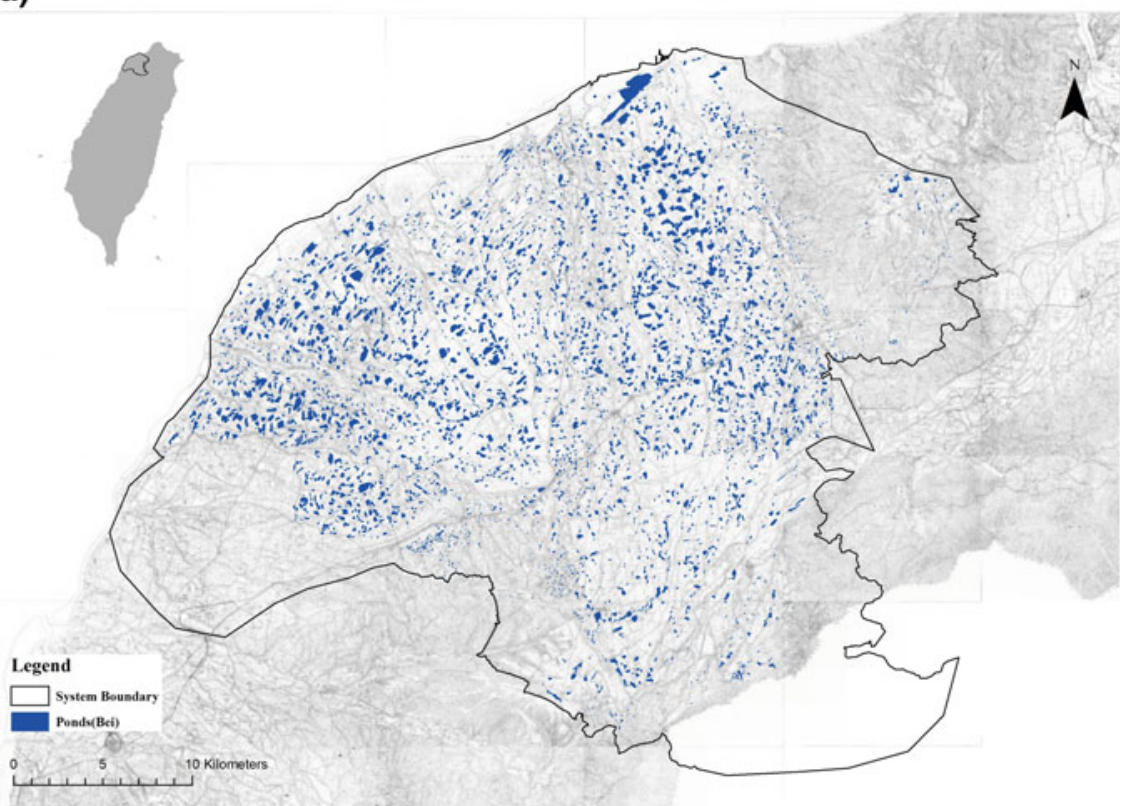

(b)

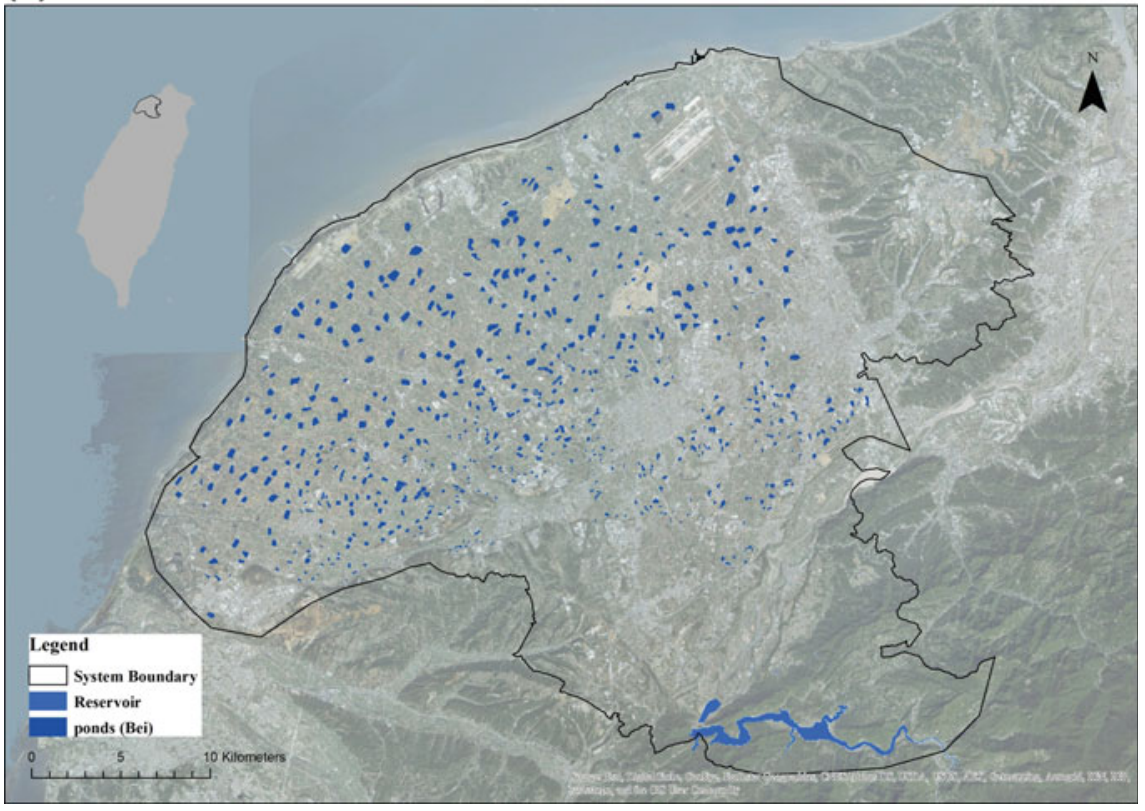

Fig. 2 Ponds at Taoyuan tableland: a On "Maps of Taiwan Fortress" in 1904 (above), b More than a hundred years on current Google earth (below); released under a Creative Commons AttributionNonCommercial-NoDerivatives 4.0 International License 
of China handed Taiwan to Japan in 1895, the new colonial government issued a bill in 1901 transforming the private management into government-run public facilities. In 1913, a severe drought occurred in the Taoyuan area, prompting the colonial authority to initiate the construction of the Taoyuan Main Canal, a water network linking all existing ponds with canals (TMC, see Fig. 3a), with an irrigation altitude of less than $110 \mathrm{~m}$; this was according to the canal inlet location for water to transport by gravity to achieve in the Taoyuan tableland terrain (See: Chen 2003a). The plan also aimed to bring in water from sources over mountains. In short, it managed the water resources of the region as an integrated system. It also reorganized, rearranged, merged and modified the historic ponds into fewer than three thousand modern ponds and by this expanded the whole volume of water supply. TMC Construction began in 1916 and was completed in 1924 (See: Chen 2003a). At its inauguration, a memorial tower was set up for the people who had died during construction. Taoyuan Irrigation Association (TIA) has operated this canal system thereafter and increased the irrigated farmland from twelve thousand to twenty-five thousand hectares (See: Chen 2003b).

\section{The Shihmen Reservoir and the Shihmen Main Canal System}

A significant portion of the Taoyuan tableland area above the elevation of $110 \mathrm{~m}$ was not included in the TMC irrigation network. Residents there continued to suffer from the unstable water supply during dry seasons, especially in the drought of 1953-1954. As part of official efforts to improve Taiwan's postwar agricultural infrastructure and economic self-sufficiency, the Shihmen Development Commission was founded in 1955 to oversee the construction of the Shihmen Reservoir (Shihmen Reservoir Construction Committee 1966). This reservoir was the fruit of collaboration with American funds and technology, and its initial design went through some major changes after the collapse of the French Malpasset Dam in 1959. During the construction period, in 1961, TIA began to operate a large-scale rotary irrigation system in its irrigation area, to conserve water usage for more farmland (See: $\mathrm{Ku}$ and Lee 2009). This water conservation system distributed water to different service areas by turns, not incessantly, and thus provided each unit of farmland just enough amount of water needed. With this more efficient use of water, the TMC system created nearly 4700 ha of new irrigation areas. After the reservoir was completed in 1964, the water stored could often reach $200 \mathrm{~m}$ elevation. The Shihmen Main Canal (SMC, see Fig. 3b) was built in 1974 to irrigate the areas at the elevation of 110-195 m; a new local water management organization, Shihmen Irrigation Association (SIA), was founded to be in charge of it (See: Shihmen Reservoir Construction Committee 1966). Thereafter, the new reservoir served as a pivot for both TMC and SMC systems, extending the irrigated area to up to more than forty-two thousand hectares in the tableland region. 
(a)

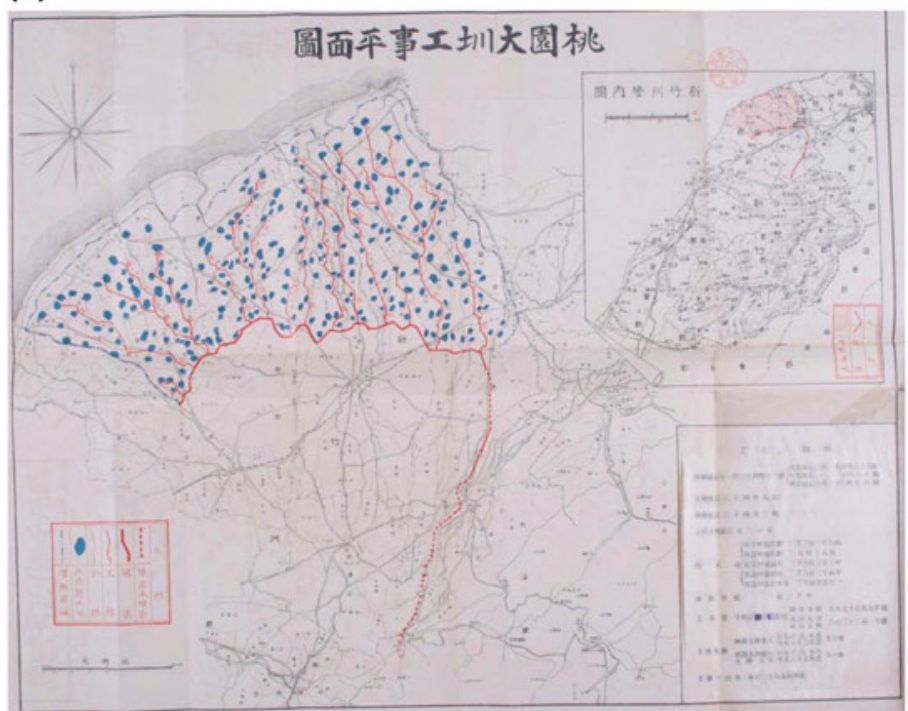

(b)

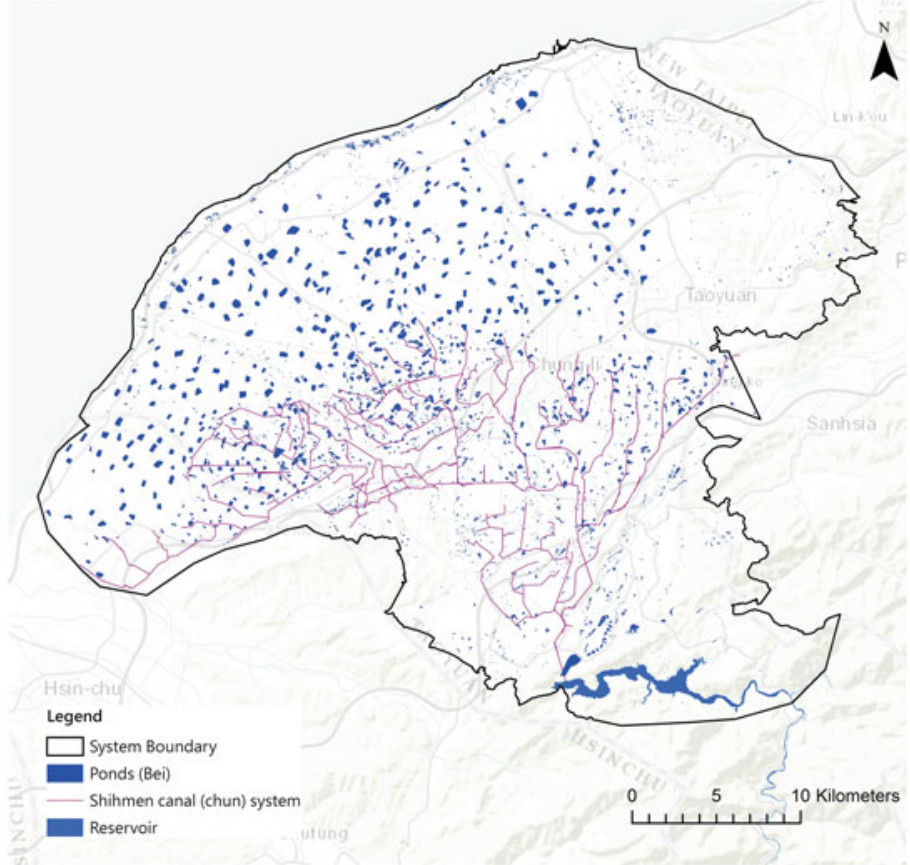

Fig. 3 Canal systems and Reservoir on Taoyuan tableland: a Taoyuan Main Canal fortification plan in the 1920's (above), b Shihmen Reservoir and Shihmen Main Canal system in 2016; released under a Creative Commons Attribution-NonCommercial-NoDerivatives 4.0 International License 


\section{The Cultural Heritage of the Taoyuan Tableland Water System}

People in the Taoyuan tableland say "two droughts in three years" to describe the uneven distribution of rainfall (See: Yu 2017). Natural water sources are scarce, especially in the drought season from September to April. In the pre-modern period, conflicts between families or clans over water rights occurred frequently. Artificial ponds were their solution to this severe water shortage, saving rainwater for dry seasons and allocating water to daily life and agricultural uses. Ingeniously, early engineers used no windmills or pumps in this water system; rather, they sited these water facilities according to the terrain, so that gravity would help transfer water. The ponds partially ceased the feuds over water and strengthened social stability. Land cultivation and migrant communities flourished with steadier water supply.

However, the new water could not completely meet the demand, and in dry years, clashes between clans unavoidably continued. When population and agriculture expanded, the need for water grew too, leading to more social upheavals. Hence, the constructions of the water system with ponds, Taoyuan Main Canal, Shihmen Reservoir, and Shihmen Main Canal helped settle these conflicts. Since water was so precious, ponds and canals became an important part of daily life and rural landscape in the region. Many places were named after their local ponds. For example, “Lun-Bei (崙埤)" means “pond on the hill”; “Bei-Liao (埤寮)”, literally “cabin by the pond", indicates the existence of a cabin for the pond guard in the past (See: Yu 2017).

Building a pond or a canal was not an easy task. It required the efforts of an entire family or clan. Thus, a pond or a canal was often the property of an extended family, closely bound to its prosperity. And people located most ancestral temples near ponds or canals. Thus, the tangible and intangible elements of Taoyuan's water landscape are crucial to the region's culture.

This water system was a hybrid of technologies from the Dutch VOC, Taiwanese indigenous people, Chinese immigrants, Japanese colonists, and American engineers. It is an excellent demonstration of how driving forces from different corners of the world have contributed to Taiwan's history. It also exemplifies the intensified interactions between different regions-globalization-since the era of Columbus. In recognition of the culture and history embodied in this distinctive water landscape, in 2009 the Taoyuan tableland water system was listed as a potential world heritage site in Taiwan.

\section{Threats to the Water Heritage, Ecosystem, and Society on the Taoyuan Tableland}

Facing challenges from land development and climate change, this water management system has become a battlefield of growing demands for lands and water. 
Postwar Taiwan witnessed an economic and demographic boom. Taoyuan tableland's population grew from less than 500,000 in 1960 to 730,000 in 1970, crossed over one million in 1980, and reached two million in 2010. This explosive growth led to the destruction of historic irrigation ponds, reducing their number by more than $70 \%$ in the past decades: many ponds and canals have been filled up for residential blocks, schools, government facilities, industrial plants, public roads, and the island's largest international airport. The consequence: The water supply capacity of Taoyuan's irrigation system dropped from 34,568 ha of farmland in 1970 to 28,241 ha in $1984,26,235$ ha in 1989 and 25,967 ha in 1999. This drop in capacity also reflected the shrinking of agricultural land area as a whole over this period. Before the 1970s, agricultural sectors took $95 \%$ of all water supplied by Taoyuan's water management system. Now the agricultural portion has been reduced to $50 \%$, with domestic and industrial demands increased to $50 \%$.

With the reduction of farmland, many water rights for agriculture gradually shifted to non-agricultural sectors. Today, Taoyuan's water management system supports agriculture as well as the domestic water usage of the whole Taoyuan tableland and half of the Taipei basin, the island's largest metropolitan area, or daily water for five million people daily water and agricultural irrigation of thirty-six thousand hectares'

It is standard practice in Taiwanese water right administration to put domestic and agricultural uses before industrial demands. However, when a drought warning is announced, the government has prioritized industrial water use to prevent significant economic losses and has compensated the farmers affected. In the long run, this adjustment damages agricultural food production. With the threat of global climate

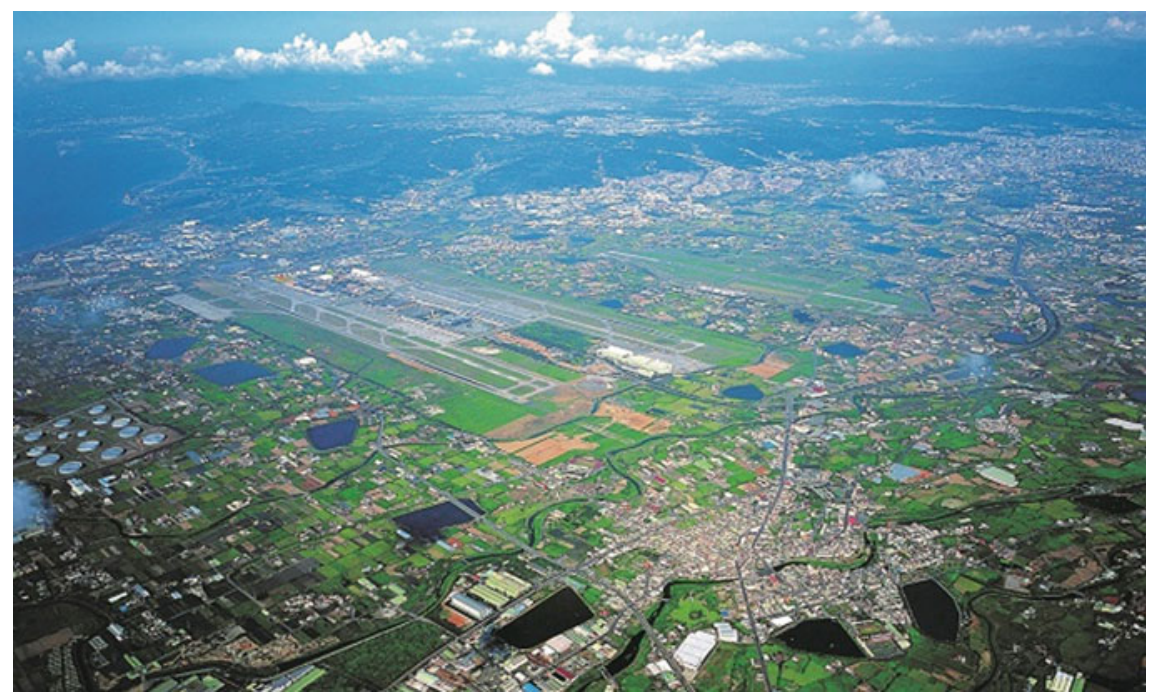

Fig. 4 Aerial view of Taoyuan Aerotropolis region in 2014 (Photograph Credit Jnfakimo CC BY SA 2.0) 
change becoming acute, the allocation of water in drought seasons has become a crucial issue, especially with the aforementioned shift of water rights away from agriculture.

In 2008, a Taoyuan Aerotropolis development plan, which had been under discussion since the turn of the century, was officially announced, forecasting a new and tremendous change for the environs of the Taiwan Taoyuan International Airport in the Taoyuan City (See: Construction and Planning Agency 2014). Supported by the city and the Ministry of Transportation and Communications (MOTC), the Aerotropolis plan aimed to expand the international airport and make the surrounding 6800 ha into a new city. Within the proposed area were some 4600 ha of farmland with ponds and canals (see Fig. 4), about one-tenth of all the agricultural land on Taoyuan Tableland. The plan proposed adding 3000 more hectares, which would dislocate over 26,000 people from farmlands and villages. This has been viewed as the worst forced community demolition in Taiwan's history, hurting both human rights and social sustainability.

The acquired farmlands were to be converted into zones for business, manufacturing, exhibition, leisure, and housing (see Fig. 5a), permanently altering the landscape of the Tableland, the network for water distribution, and the tableland water management heritage. Specifically, paving farmland and backfilling water bodies (e.g. ponds and canals) would significantly reduce the capacity of the area to retain water. The loss of this capacity would then make the surrounding region of Taoyuan Aerotropolis much more vulnerable to both droughts and floods-increasingly frequent in recent years as climate change haunts Taiwan. And the disappearance of farmlands and water bodies means the loss of their temperature moderating functions. This would worsen the existing severe heat island effect of global warming. In addition, two side effects of the development plan might well imperil social stability: The reduction of farmlands could damage Taiwan's food production and threaten the island's food security during extreme weather conditions, and the massive-scale forced relocation would create discontent and conflicts.

The Aerotropolis plan roused debate among all sectors of Taiwanese society. Some people worried that the economic globalization accompanying the new Aerotropolis would worsen the competition for water, labor, and land resources between sectors. Some argued that the proposed Aerotropolis area was unnecessarily large, making the project too costly, and imposing some irreversible impacts on the ecosystem of the region and the life of local residents. Heritage conservationists objected that the construction of the Aerotropolis could destroy two important pieces of cultural heritage, an old navy airport, and the pond-canal system. 


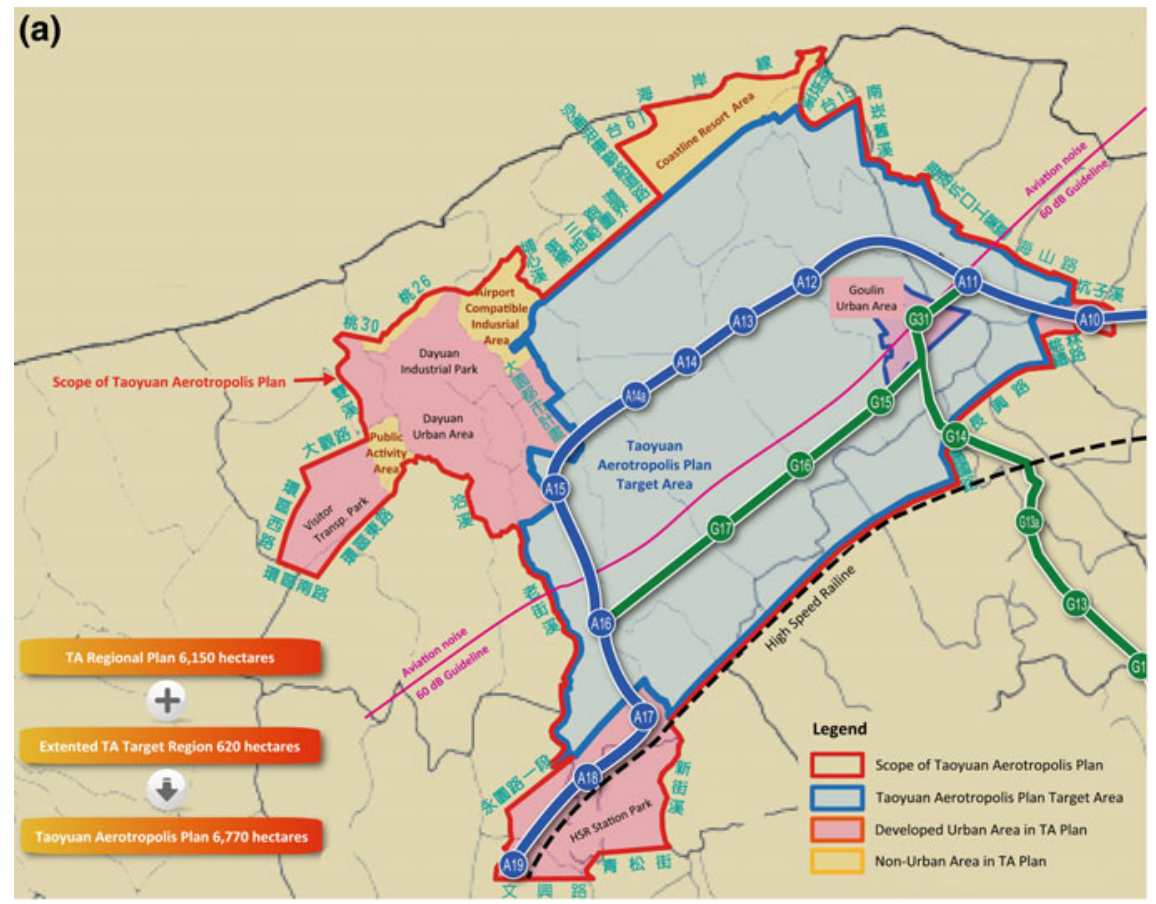

(b)

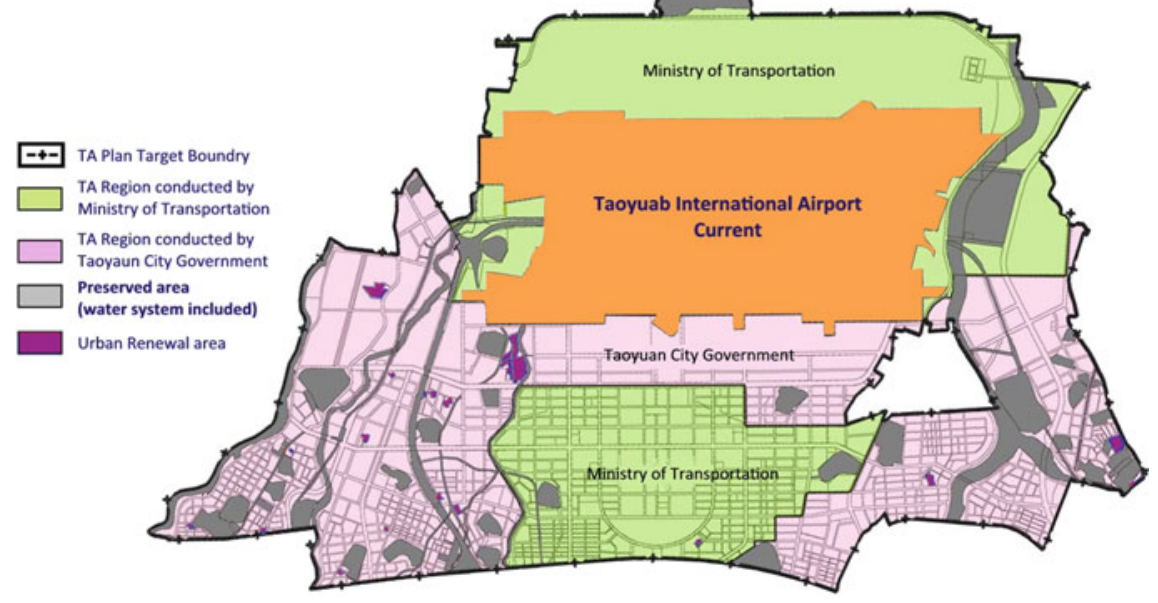

Fig. 5 Taoyuan Aerotropolis Plan layout: a Initial development version (above), announced in 2012; b Cultural water heritage preserved version (below), announced on August 11, 2017; released under a Creative Commons Attribution-NonCommercial-NoDerivatives 4.0 International License 


\section{The Legal Evolution of Cultural Heritage Preservation in Taiwan}

The Cultural Heritage Preservation Act (CHP Act) of 1982 was the legal cornerstone of Taiwan's heritage preservation. It was the fruit of a growing awareness of heritage in the late 1970s, when cultural policies took a turn to embrace the lives of local and living people.

In 1999, a severe earthquake in central Taiwan killed thousands of lives and destroyed hundreds of thousands of buildings, both historic and modern. In order to recover from the devastation, heritage conservationists and cultural professionals initiated many comprehensive community development programs on local scales. When they tried to apply the CHP Act in these projects, however, the Act's defects became apparent: its targets of preservation were single objects such as architectural works and their ancillary facilities, archaeological or historical sites, and antiquities most of which were only loosely connected to the communities they belonged to. Moreover, the Act mandated that the only way to preserve a heritage site was to "freeze" it in its earliest shape and historical context, preventing people from creating new meanings and functions. Not surprisingly, communities were often against this kind of preservation of their heritage. When something costs a lot to maintain but brings no benefit - be it material, emotional, or spiritual-no community would bother to keep it. Hence, the campaign for a revision of the CHP Act that would mobilize bottom-up or community engagement in heritage preservation and reutilization.

The second version of the CHP Act (called CHP Act 2.0), enacted in 2005, provided the legislative ground for public participation in heritage management. It broadened the study, protection, and management of heritage sites or systems beyond a small group of experts (See: Lin 2005). However, it continued to view heritage preservation as many single, unconnected tasks and did not integrate heritage management with regional development plans. This weakness of the newer CHP Act has been all too visible in many recent attempts to reallocate land and water resources.

\section{Public Participation as Conflict Resolution in Preservation and Development}

Many actors-including historians, writers, artists, environmentalists, rural protectors, farmers, ecologists, and even water engineers-formed an alliance for the preservation of Taoyuan's water heritage infrastructure as heritage. They demanded that policymakers include the public in the early stages of urban and land planning projects, and deployed their expert knowledge to demonstrate that the historic ponds and canals are indispensable to today's Taoyuan society. For example, experts in water resources showed that water storage and conveyance capacity in agriculture are essential to human existence in the face of climate change. Scientists noted that biodiversity in ponds prove that a water system is a valuable repository of treasures 
for local ecology. Historical traces of water management reflected the transformation of an immigrant society during the seventeenth and eighteenth centuries. Poetry, photography, and other forms of art depicting Taoyuan's water landscape illuminated local people's memories of the past. Moreover, both Taoyuan and Shihmen irrigation associations had come to understand the value of rice paddies to the bionetwork and began working with local communities to preserve the memories and landscapes associated with Taoyuan tableland's irrigation ponds and canals system.

This alliance of protectionists raised widespread awareness in Taoyuan society of the area's water heritage and heated up the debate over the Aerotropolis plan. Policymakers and land developers for the project at first proposed to replace the backfilled ponds with community parks, not the more profitable residential or commercial quarters. At public hearings, the protectionists responded that the reduced water volume would still be insufficient for the area's hydrologic cycle. The developers then adjusted the plan so that there would be no net loss of water, which was rejected again as the project would still damage biodiversity. During these exchanges of opinions, one plan even proposed relocating water habitats. But the opposition's key point, which in the long run won the argument, was in a different realm altogether: The significance of Taoyuan's water heritage system lies not merely in the locations of associated monuments, its scale, its history, or its contribution to the profit of different sectors. Rather its significance is in its holistic context: That residents of Taoyuan could relate each of these issues and water heritage systems as a whole to their everyday lives and memories.

With the aid of social media and online forums, stories about the endangered ecosystems, reports on unfair compensation to local farmers, and others spread quickly and widely. In the spring of 2014, a political storm, the Sunflower Movement, in Taiwan prompted many young people to be engaged in all kinds of social activism and to demand greater transparency in policy making. Unsurprisingly, many focused on the already controversial Aerotropolis plan. Public hearings were livestreamed online by volunteers to invite greater participation in forming consensus. At the end of the year, when voters elected a new mayor, they chose the candidate who promised to thoroughly review and modify the Aerotropolis project. As more and more people expressed personal concern over the fate of the ponds and canals, it became more difficult for the developers to win public support for the project.

Then a severe drought ignited an even broader discussion on water resource management. In September 2014, the amount of rainfall on the Taoyuan tableland was only $20 \%$ of the normal seasonal average. In January 2015, a full-scale water right shift transferred all the irrigation water to the domestic sector. Cultivation was suspended on 27,000 ha of farmland; about 20,000 farmers found it difficult to survive the drought, even with higher than usual compensation. This sparked great anger among the farmers and society. Meanwhile, several farmers in the region were unaffected by the water suspension, as their respective ponds helped them maintain irrigation. The difference between farmlands with ponds and those without poignantly illustrates why the pond-canal-reservoir system should not be sacrificed for the profits of industrial economic growth. People wondered if the Aerotropolis project might cause further setbacks from which the region would not recover. 
Heritage preservationists now joined with other groups to promote another amendment of the CHP Act 2.0. They suggested that public participation and narrative weaving were essential for preserving non-traditional heritage structures such as water management networks. This new concept of narrative and heritage was adopted in an amended CHP Act of 2016 (aka CHP Act 3.0). The new stricter rules significantly increased the sustainable risk for the Taoyuan Aerotropolis plan, adding to the maintenance and financial burden of the developers. Any failure to fulfill their promises - whether of no net loss of the water body, water habitat relocation, adjustments for social and environmental impacts, or other concessions-would incur further punitive payments.

Several years had passed since the 2008 announcement of the Aerotropolis project; the government and the developers had failed to soothe opposition or start major constructions. Instead, new obstacles such as the CHP Act 3.0 rose during this long process of negotiation. Eventually, the Aerotropolis plan was revised (see Fig. 5b). The Taoyuan city mayor decided to exclude all disputed areas from the project; this major change meant that the whole water heritage system and its cultural landscape could be preserved.

\section{Conclusion}

In Taiwan, it has been more difficult to draw public attention to water heritage systems than to monuments, historic buildings, or archaeological sites. Preserving them is thus a challenging mission. In past decades, devoted preservationists in Taiwan have learned that the accumulated tacit knowledge of water heritage systems may be excavated from local community's oral traditions and legends and be used to express the residents' loved memories and feelings. When professional investigations, public awakening, and social mobilization all come together to form a common ground for public participation, one result can be that people cherish a water heritage system even more; another might be that the system brings economic profit.

A distinctive characteristic of water facilities is that they always work and function in a network. That is, a water heritage structure would consist of multiple sites dispersed in different locations. Except for grand constructions such as dams or canals, most of these essential components appear mundane and without historical or cultural value. However, water facilities are so essential to daily life that, like the air people breathe all the time without always noticing its existence, they can be easily introduced into different narratives that cover all aspects of human life, society, and history. A whole network of water facilities could be represented as a heritage or a "water museum", with participatory narratives woven around the network or system.

Water heritage, particularly those systems still functioning, is more relevant to local people's daily lives than the heritage of other categories. Any change to these systems, as the case presented here shows, would affect more stakeholders and raise greater public concern. This is why, at the announcement of the Aerotropolis Plan, local farmers and residents-whose lands and existing lifestyle were put 
under threat-stood up with professionals to voice their concerns in the first place. The protection of the Taoyuan water system was thus initiated by a mixed troop of people from various backgrounds and with a range of issues to address. This diversity helped them reach to more sectors of Taiwanese society and gain wider public support. As the case of the Taoyuan water heritage shows, when a local community becomes interested in the waters around it, public opinion can form a protective shield for endangered heritage against new urban development plans.

\section{References}

Chang Y-C (2016) Report of strategical planning for engaging world water system heritage program. Water Resources Planning Institute, Water Resources Agency, Ministry of Economic Affairs, Taiwan (in Chinese)

Chen H-T (2003a) From manmade ponds to Taoyuan main canal: the development of irrigation system on Taoyuan Tableland. Dong Hwa J Humanit 5:183-208 (in Chinese)

Chen C-P (2003b) A survey of Taoyuan main canal and Guan-Fu canal systems. Executive Yuan, Taipei (in Chinese)

Construction and Planning Agency, Ministry of the Interior (2014) Proposed development plan for Taoyuan international airport and its surrounding areas (in Chinese)

Government of Taiwan (1996) Taiwan map of 1904. YLib, Taipei (in Chinese and Japanese)

Hsu Y-D, Li H-Y (2006) The preservation of architectural heritage in a multicultural country. J Taiwan Land Res 9-2:75-96 (in Chinese)

International Council on Monument Sites (2008) The ICOMOS charter on cultural routes

Ku Y-W, Lee T-H (2009) Interview of Kuo-Yun Fu, Director of Rotary Irrigation. Shihmen Reservoir. http://epaper.wra.gov.tw/Article_Detail.aspx?s=3CCE023F9B10350C (in Chinese)

Lin H-C (2005) https://www.boch.gov.tw/information_189_49251.html (in Chinese)

Lin Y-H (2011) A brief History on cultural heritage preservation of Taiwan. Bull Natl Museum Taiwan 64-1:75-106 (in Chinese)

Lin H-C (2014) The legalization of Taiwan's post-war heritage preservation. J Cult Resour 8:27-55 (in Chinese)

Lin C-H (2017) Cultural heritage preservation 3.0 - cultural and ecological system in water system heritage. International Water Heritage Forum, Bureau of Cultural Heritage, Taichung of Taiwan (in Chinese)

Liu Y-Y (2003) The Wufeng family awaits daylight. Control Yuan, Taipei (in Chinese)

Shihmen Reservoir Construction Committee (1966) Records of the construction of the Shihmen Reservoir. Shihmen Reservoir Construction Committee, Taoyuan (in Chinese)

Yu S (2015) Report of the pilot framing for fused innovation with water and heritage of Taiwan. Bureau of Cultural Heritage, Ministry of Culture, Taiwan (in Chinese)

Yu S (2017) Report of investigation and evaluation of water system heritage in Taiwan (I). Bureau of Cultural Heritage, Ministry of Culture, Taiwan (in Chinese)

Sinite $\mathbf{Y u}$ is a research fellow at Taiwan International Institute for Water Education. He has taught at National Chiayi University and Huafan University. He started his professional career in soil and water resource management and water treatment; he later pioneered the research of water heritage in Taiwan. He now seeks to cultivate awareness of water heritage among different sectors of Taiwanese society. 
Chung-Hsi Lin is a professor of cultural heritage conservation at National Yunlin University of Science and Technology, Taiwan. A prominent advocate in Taiwan for innovative cultural theories and community participation in heritage conservation, Lin writes on a wide range of topics to prompt public discussion on cultural policies. He now also serves as an advisor to Taiwan's Ministry of Culture.

Hsiaoen Wu is an assistant research fellow at Taiwan International Institute for Water Education. She researches the historical and cultural contexts in which heritage was created, used, and perceived. As an author of popular history, she writes stories about the remote past to help people understand connections between the past and the present.

Wenyao Hsu is an associate research fellow at the Taiwan International Institute for Water Education. Her research explores citizen participation in water resource management and urban planning. She has conducted many water-related projects and authored multiple articles, including "The Citizen Participation Plan for Promoting the Operation and Management of Zengwen Reservoir."

Yu-Chuan Chang is a professor of tourism management at Hsing Wu University, Taiwan. Trained as an agricultural engineer, he acquired extensive experience in irrigation systems during the early years of his career. He now works primarily on the sustainable use of water for irrigation and the restoration of historic irrigation canals.

Open Access This chapter is licensed under the terms of the Creative Commons AttributionNonCommercial-NoDerivatives 4.0 International License (http://creativecommons.org/licenses/bync-nd/4.0/), which permits any noncommercial use, sharing, distribution and reproduction in any medium or format, as long as you give appropriate credit to the original author(s) and the source, provide a link to the Creative Commons license and indicate if you modified the licensed material. You do not have permission under this license to share adapted material derived from this chapter or parts of it.

The images or other third party material in this chapter are included in the chapter's Creative Commons license, unless indicated otherwise in a credit line to the material. If material is not included in the chapter's Creative Commons license and your intended use is not permitted by statutory regulation or exceeds the permitted use, you will need to obtain permission directly from the copyright holder.

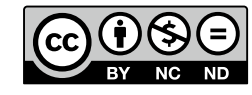

